\title{
DIGITAL MEDIA AND CIVIC ENGAGEMENT ON HEALTH RISKS OF SMOKING AMONG DRIVERS IN ANAMBRA STATE
}

\author{
Stephen Afam Kenechukwu, PhD \\ Department of Mass Communication, \\ Federal University Oye-Ekiti, Ekiti State. \\ afamkene@yahoo.ca
}

\begin{abstract}
Smoking is the inhalation and exhalation of fumes of burning tobacco and other dangerous nicotine substances that endanger health. It is also a learned behaviour capable of causing addiction. The study examined civic engagement through digital media on health risks of smoking among drivers in Onitsha, Anambra State. The study focused on drivers of registered Mass Transit companies: Eastern Mass Transit and Onitsha South Mass Transit. The study was anchored on two theories: grounded theory of smoking decision which explains pre-and-post effects of smoking quitting, and mediatisation theory which examines the long-term structural change in the role of media in culture and society. The study adopted a survey of drivers of select Mass Transit companies in Anambra State. This was to ensure that these drivers were studied in their varying work atmospheres concerning smoking. Findings of the study showed that drivers of both companies make effective use of digital media for information on the dangers of smoking while driving and erring drivers are adequately penalised. Based on the findings of this study, it is recommended that media messages on the dangers of smoking tobacco or other dangerous substances on the wheel should be sustained. It equally recommended psychological tests on drivers before recruitment.
\end{abstract}

Keywords: Smoking, Digital media, Civic engagement, Health risks.

\section{BACKGROUND OF THE STUDY}

Driving is a skill of operating an automobile either for commercial purpose or personal use. Driving provides a means of transportation and a form of occupation. Individuals also drive others as private drivers. A critical factor in efficient driving is the mental state of a driver. It is, however, difficult to evaluate mental state of a driver except through observance of driving skills and perceptibility to alcohol intake or smoking habit.

The effects of tobacco smoking among drivers continue to generate health and safety concerns. In a study on 'The prevalence and factors associated with tobacco smoking behaviour among long-distance drivers in Lagos, Nigeria', Ozoh, Akanbi, Amadi, Vollmer and Bruce (2017) observe that 25-85\% commercial drivers have a high prevalence of cigarette smoking. This finding was found from a study of long-distance commercial drivers. The above statistics point to safety concerns as regards driving and smoking. Often, these substances are taken some minutes before driving or in the course of driving.

People smoke different substances such as cigarettes, marijuana, and other inhalable nicotine substances. Among drivers, driving is a complex task which may be undertaken by individuals under the influence of substances with psychoactive effects. These substances are capable of making them 'high' or may have other psychological effects. Driving while impaired by any substance is dangerous. However, specific types of nicotine substances stimulate driving in different manners. While dealing with the duality of traffic accidents and road safety, Alonson, Esteban, Useche and Faus (2017) state that smoking while driving is one of the factors that, despite the social beliefs and/or misconceptions, causes a large number of injuries and deaths worldwide. The consensus is that smoking before or during 
DOI: doi.org/10.47851/naujocommed.v2i1.107

driving affects the mental state of a driver, thereby making him or her vulnerable to accidents.

Many advocacies have been initiated to orientate drivers on the dangers of smoking while driving. This is the assumption of civic engagement. It refers to the civic participation of individuals or groups addressing issues of public concern (Delli, 2017). Civic engagement provides a common platform for social interactions. It is the ability to influence choices through collective action (Camino and Zeldin, 2002). The result of active civic engagement programme is assessed through perceivable behaviour from participants. In the case of driving and smoking, there have always been periodic civil engagements with stakeholders in the transportation section. This type of engagement offers participants access to information and defined benefits.

One viable medium of civic engagement is through the use of digital media. A digital medium runs on the encoded machine-readable format. The use of smartphones has widened information reach and dissemination. Digital technologies can facilitate the generation and communication of data, thereby opening new ways for individuals to get their voices heard in the public sphere. We depend on advanced technological devices to access information. A driver receives information through his mobile phone and can also react to information from the mainstream media.

\section{STATEMENT OF RESEARCH PROBLEMS}

The question of safety and health implications of smoking while driving has been at the forefront of media campaigns on the dangers of smoking among drivers. A more worrisome problem is the type and time of smoking tobacco or other dangerous substances before driving. In general, smoking includes all inhalable substances that are psychoactive; however, some inhalable elements exert more destructive influences on some people than others. Cigarette smoking contains nicotine substance which is a toxic alkaloid. On the other hand, other dangerous inhalable substances like cannabis and marijuana are so poisonous and intoxicating that they impair vision and mental alertness. The crux of this study is not on the religiosity of smoking but on the effects of smoking by commercial drivers, whether before and during driving. The time of intake of cigarette smoking matters a lot in studying the attitude of an individual driver with driving skills. Does the time of ingestion of cigarette and other toxic inhalable substances such as marijuana affect driving? The rate of reaction of these substances varies among drivers. While some drivers seem feel slight effects of cigarette, those that inhale marijuana may suffer dizziness on a wheel, unruly behaviour to passengers and resort to reckless driving leads to an accident.

The effectiveness of the medium of communication and civic engagement programmes on the dangers of smoking while driving poses challenges. Commercial driving is a type of job in which a commercial driver hardly has time for family let alone using digital media for information. The Nigeria Highway Code makes it a severe offence to answer phone calls while driving. This is purely a safety measure that protects drivers and passengers from accidents due to divided attention. The problem is that health messages using digital media such as phone and other Internet-able devices may not get to target drivers except when such information comes at the appropriate time at the end of day's work.

There is also a problem on the effectiveness of nature and timing of civic engagements among commercial drivers. Like in the case of using digital media for dissemination of health information, choosing the appropriate time for collective civic engagement with health 
DOI: doi.org/10.47851/naujocommed.v2i1.107

experts may be unattainable. This is because; commercial driving is time-bound, and passengers are usually impatient. This simply means that a mutual face-to-face engagement with drivers may be ineffective. In its place, management of Mass Transits such as Eastern Mass Transit and Onitsha South Mass Transit resort to the use of house organ (in-house news outlets) to inform drivers on management policies. The study studies the above problems visà-vis the dangers of smoking among commercial drivers.

\section{RESEARCH OBJECTIVES}

Generally, the objective of the study is to examine the effectiveness of digital media and civic engagements in information dissemination on the dangers of smoking among commercial drivers. Specifically, the following are the objectives of the study:

i. To investigate attitudes of drivers of Eastern Mass Transit and Onitsha South Mass Transit to smoking and driving.

ii. To evaluate management policies of select Mass Transit companies on smoking and driving.

iii. To determine the effectiveness of digital media in information dissemination on the dangers of smoking and driving among drivers of select Mass Transit companies.

iv. To determine the effectiveness of civic engagement of select Mass Transit companies on the dangers of smoking and driving.

\section{RESEARCH QUESTIONS}

The following research questions were formulated to strengthen the study:

i. What are the attitudes of drivers of Eastern Mass Transit and Onitsha South Mass Transit to smoking and driving?

ii. What are management policies of select Mass Transit companies on smoking and driving?

iii. To what extent is digital media effective in information dissemination on the dangers of smoking and driving among drivers of select Mass Transit companies?

iv. To what extent is civic engagement effective on the dangers of smoking and driving among drivers of select Mass Transit companies?

\section{REVIEW OF RELATED LITERATURE \\ Smoking: An Overview}

Smoking includes all forms of inhalable substances adjudged to have harmful effects on health. It consists of all chemical substances that induce behavioural changes in users. Encarta (2009) defines smoking as the inhalation and exhalation of the fumes of burning tobacco. Leaves of the tobacco plant are smoked in various ways. After a drying and curing process, they may be rolled into cigars or shredded for insertion into smoking pipes. Apart from nicotine that is a principal constituent of all inhalable substances, smoking such as cigarette often leads to addiction. The smoking habit and addiction to nicotine usually begin at an early age. Smoking is the act of inhaling and exhaling the fumes of burning plant materials. A variety of plant materials are smoked, including marijuana and hashish, but the act is most commonly associated with tobacco as smoked in a cigarette, cigar, or pipe. The primary constituents of tobacco smoke are nicotine, tar (the particulate residue from combustion), and gases such as carbon dioxide and carbon monoxide. Smoking is hazardous to health (Hilton, 2015). It is, therefore evident that smoking is associated with copied behaviour which is aggravated by addiction. 
Benjamin (2010) explains that the poisons in smoke pose a danger right away. Sudden blood clots, heart attacks, and strokes can be triggered by tobacco smoke. Toxins in tobacco smoke disrupt the way a smoker's body heals itself. Even smoking a cigarette now and then is dangerous to health such as possible sudden heart attack and other chronic respiratory ailments. A driver that smokes is most likely to experience a heart attack on the wheel. The types of smoking habits that affect driving are: (a) cigarette smoking and (b) cannabis smoking.

Cigarette Smoking: Cigarette is often seen as a light but dangerous inhalable substance. This is in comparison with other heavy inhalables such as cannabis/marijuana. One significant constituent of a cigarette is nicotine which causes addiction to cigarette smoking. Nicotine changes the way a smoker's brain works and causes you to crave more and more nicotine. These powerful cravings make it hard for you to think about anything else (Benjamin, 2010). The study of Ozoh et al. (2017) found that 25-85\% of commercial drivers have a high prevalence of cigarette smoking. The study further found that there is a high rate of use of other psychoactive substances among long-distance drivers.

Cannabis Smoking: This is another psychoactive substance derived from herbs. It is popularly known as cannabis Sativa or marijuana. This type of inhalable material is deadlier than cigarette smoking. Hartman and Huestis (2013) state that cannabis is the most prevalent illicit drug identified in impaired drivers. This substance is often used by drivers as sedatives to be calm. This induced calmness often lead to drowsiness and subsequent loss of control of the car. Drivers under the influence of marijuana are most likely to experience impaired vision. This is because; driving while impaired by any substance is dangerous.

\section{Health Risks of Smoking and Driving}

Many studies have been done on the health risks of smoking and driving. In a survey of 'the effects of smoking on society: a case study', Gupta and Kumar (2018) observe that smoking is very hazardous and may be responsible for road accidents when it is used by a person who is driving. In this regards, smoking and driving creates psychological effects while driving. A chronic smoker will surely take some sticks of cigarette before or during driving. This validates the place of time of smoking concerning exposure to road accidents. A driver under the influence of inhalable substances will experience visual disturbance and increases the risk of heart attack even while driving.

Alonso et al. (2017) agree that inhalable substances are dangerous. This is because; smoking while driving causes a large number of injuries and deaths worldwide. Smoking while driving causes visual impairment, distracts a driver and causes slower reaction time and a worse adaption to the conditions and demands of the vehicle, the road and the environment (Sullman, 2012). Apart from respiratory problems associated with smoking, a driver who smokes during the operation of a vehicle increases its potentiality to be involved in an accident. This is because; a driver under the influence of psychoactive substance is inclined to distraction and recklessness on the wheel.

National Safety Council (2017) observes that driving under the influence of cannabis is a significant public safety concern. Drug-impaired driving endangers both driver and passengers. Regrettably, some commercial drivers smoke psychoactive substances before driving. The duration ranges from smoking about one hour to driving and some minute 
DOI: doi.org/10.47851/naujocommed.v2i1.107

before driving. It should be noted that there are stiff regulations guiding driving for registered mass transit. Drivers of registered mass transits claim they do not smoke nicotine substances while driving. This is due to company's policies that penalise offenders with suspension or outright sack. Among commercial drivers of unregistered transportation companies where there is a lack of adequate regulatory mechanism, drivers tend to smoke substances some minutes before driving. This dangerous trend is often witnessed in motor parks. A study carried out in the United States on the intake of alcohol and cannabis among drivers found that marijuana is the most widely-consumed illicit substance worldwide. This finding differs from the Nigerian case because stringent rules and agencies regulate driving within accepted regulatory standards.

Generally, smoking is dangerous because of the constituent psychoactive substance that is inhaled. Oladepo, Oluwasanu and Abiona (2018) hold that tobacco use is a significant risk factor for non-communicable diseases and policy formulation on tobacco use. This position is collaborated by Benjamin (2010) and Hartman and Huestis (2012) that inhalable nicotine substances increase lane weaving and impaired cognitive function. This impaired coordination distorts a driver's sense of perception. Some drivers start seeing 'fantasy visions' while on wheels.

\section{Smoking and Driving: Reviewing Safety Problems}

Safety of driver(s) and passengers is key to safety policies of any government and transportation system. A driver under the influence of inhalable substances is most likely to be reckless in driving, aggressive to passengers or may develop a total or partial mental disorder. Regrettably, a psychological test is rarely administered on drivers at the point of recruitment. Most commercial drivers for both registered and nonregistered mass transits do not place a premium on psychological status of potential drivers. Standard criteria for recruitment may include: (a) acquisition of current Driver's Licence, (b) evident of previous driving experience with a notable transportation company, and (c) referral by a driver. In most cases, issues of past driver's susceptibility to drunkenness, smoking habits, recklessness, aggressive behaviour and even educational qualification are rarely looked into.

As a safety measure, it is essential that transportation companies must subject drivers to periodic tests for drug level to ascertain their susceptibility to alcoholism and smoking habits. At the point of recruitment, companies rarely collate drivers' health details that can be used to determine the likelihood of car crashes. Some agencies regulate vehicular movements in Nigeria viz: Federal Road Safety Corps, Vehicle Inspection Office and the Police. The duties of these agencies vary; for instance, Federal Road Safety Corps is saddled with the responsibilities of making sure that Nigerian highways are safe from vehicular obstructions, ensuring strict compliance with existing road laws and penalising defaulters within stipulated charges.

\section{Smoking, Driving and Law}

The application of the legal framework for smoking and driving is based on the most universal law that if you intend to drive, you should avoid having any psychoactive substance in your system. Smoking tobacco in Nigeria is prohibited in public places. The National Tobacco Control Bill, NTCB 2009 regulates the manufacture, advertising, distribution and consumption of tobacco products in Nigeria. It criminalises smoking in public places including restaurants, bars, public transportation and schools. It also bans all forms of direct and indirect advertising of psychoactive substances (NTCB, 2009). 
The Federal Republic of Nigeria Official Gazette (2015) captures the position of National Tobacco Control Act, 2015 Act No. 9 concerning health and tobacco use. The Act clearly states one of its objectives in (b) as '...to give effect to the obligations to protect citizens against tobacco or tobacco product-related harms in the promotion of health and other human rights that Nigeria as a party to the World Health Organisation (WHO) Framework Convention for Tobacco Control and other related treaties to which Nigeria is party has agreed to undertake...' The above excerpt reiterated the government's resolve to regulate tobacco use in Nigeria.

States of the federation have also enacted laws regulating tobacco use in respective states. Lagos State passed a tobacco control law in 2014. Like similar law by the Federal Government of Nigeria, this law banned smoking in public places and the sale of tobacco to and by minors. The problem is whether these laws are effectively implemented. Are these laws administered on papers or are effectively implemented? The empirical results of this study attempt to provide answers to these perplexing questions. As a regulatory agency, the Federal Road Safety Corps (FRSC) has always upheld the responsibility of maintaining safe road use in Nigeria. In its Nigeria Highway (2015-2020) Code Section D: Traffic Offences at a Glance, the regulatory agency itemised 35-items of traffic offences targeted at ensuring safe road use in Nigeria.

As information regulatory body, mass media play a critical role in tobacco control, helping to counterbalance the pro-tobacco cues in the environment (O'Hegarty, Pederson, Nelson, Mowery and Wortley, 2006). At the same time, the media have an equally powerful role in influencing individuals and policymakers and have made critical contributions to the cause of tobacco control (Davis, Gilpin, Loken, Viswanath, Wakefield, 2008).

\section{The Concept of Digitisation: Exploring Digital Media}

The concept of digitisation is embedded in the idea of media convergence leading to the melding of different modes of communication. Folkerts and Lacy (2004) explain the basis of digital technology. Analog technologies transform one form of energy into another to transport content while digital technology transforms materials into a binary code of zeros and ones. Digital technologies are more efficient and carry more materials for the same amount of energy than analog transmission. In essence, digitisation affects how signals pass from one destination to another and break down incoming messages into streams of separate individual pulses of energy. With the advancement in technology, communication is consistently at a break-neck change in which obsolete communication equipment are replaced with digital devices (Kenechukwu, 2014).

A medium is a channel of communication. Digital media, therefore, are encoded media in computer-readable format and stored on computer-compatible devices. Smith (2013) defines 'digital' as any data represented with a series of digits and 'media' refers to a method of dissemination of communication. Notable examples of digital media include all computercompatible devices such as database, videogames, social media, smartphones and electronic books. These devices are visible on computers and allow for downloads of stored files. One dominant form of digital media is social media. It is an interactive form of digital media. Anand, Gupta and Kwatra (2013) assert that social media adopts Social Networking Sites (SNS) to provide cost-effective platforms to communicate with a large population. Reports suggest that social media is a very feasible option that is relatively easy to adopt, but require 
DOI: doi.org/10.47851/naujocommed.v2i1.107

adequate and appropriate human resources to maintain. Social media offers a variety of social networking sites such as Facebook, Twitter, WhatsApp etc. It implies that people use these social networks for information and relaxation.

As a medium of communication and social interaction, digital media has (a) assisted social interaction and empowers individuals, connecting the like-minded across vast distances, as well as connecting those usually separated by social, economic, cultural, political, religious and ideological boundaries and (b) offered the means to increase civic participation and facilitates the creation of communities with a common interest or cause (Nayyar, 2016). The itinerary associated with commercial driving puts to question the effectiveness of the use of digital media to disseminate health information on smoking and driving. To this effect, its effectiveness is guaranteed if such information corresponds with the time drivers are free (from driving) to access their phones for information. Driving and using a phone is a traffic offence and distracts a driver from having firm grip on a car steering gear.

\section{Civic Engagement: An Overview}

The underlying principle of civic engagement is the interaction between resource persons and participants in mobilisation towards the attainment of set goals. Engagement is simply a commitment to engage people on a social or business appointment. It, therefore shows a sense of predetermined programme of events designed to mobilise people towards set goals. Civic engagement is the ability to influence choices through collective action (Camino and Zeldin, 2002). This shows that it involves all strategies to move people to the desired change in attitude. Dubow, Devaux and Manville (2017) argue that civic engagement should be thought of not only as participation in the seismic political shifts achieved by social movements, but citizens can contribute effectively to society in a diverse range of ways. This implies that civic engagement is a two-way traffic affair in which both government and citizens contribute to the growth of organisation.

Management of commercial transportation companies does create avenues for interaction with drivers, loaders, bus inspectors on the company's policies. This interaction is usually made up of internal staff who are used to existing company's policies. Over time, drivers become tired of repeated memos and may develop nonchalant attitudes to such systems. To check against this complacency, there is need to engage experts from government and relevant agencies to interact with drivers on the dangers of smoking and other harmful health habits when driving. This is the basis of active civic engagement. The primary constraint in face-to-face engagements with drivers is that drivers hardly stay in a bus station for an extended period during rush hours from passengers. It then becomes imperative to examine the place of digital media in civic engagement of drivers on the dangers of smoking while driving. Mossberger, Tolbert and McNeal (2007) and Xenos and Moy (2007) agree that the Internet which has become the main digital (social) media outlet gives civic engagement inexcusable euphoria, abrupt and equally unjustifiable skepticism and gradual realisation that web-based human interaction does have unique and politically significant properties. With a smartphone, a driver gets an array of information on traffic rules. This digital device bridges a gap of physical participation of drivers in collective civic engagement. The challenge is the degree of Internet-compliance of commercial drivers in the use of digital media which collaborates the stance of Rheingold (2010) that people that participate online may lack the skills to effectively receive or communicate their collective concerns to large audiences. 
DOI: doi.org/10.47851/naujocommed.v2i1.107

The study was anchored on two theories: a grounded theory of smoking decision and mediatisation theory. The grounded theory of smoking decision is a theory explaining preeffects and post-effects of smoking quitting the habit. The theory holds that better understanding of the process of quitting smoking habits is through elements of spontaneity (impulsive behaviour) and preparation (reflective behaviour), and, importantly, the investment of time and cognitive effort by participants before quitting (Smith, Carter, Dunlop, Freeman and Chapman, 2017). Tobacco smoking (and other psychoactive substances) is addictive. A chronic smoker finds it challenging to quit tobacco smoking irrespective of his status or job. Examining smoking decisions could help us understand these choices as well as develop effective prevention strategies. Grounded theory, therefore, provides systematic procedures for quitting smoking habits (Lu, 2017). The decision to quit smoking is mostly dependent on each smoker and other intervening variables. A driver may choose to stop a smoking habit after a civic engagement on the dangers of smoking psychoactive substances.

A postulation of Kent Asp and further developed by Danish media scholar, Stig Hjarvard, the underlying assumption of Mediatisation theory is the recognition that it widens the framework by including new media and new areas of application. It suggests that mediatisation is a social process whereby the society is saturated and inundated by the media to the extent that mass media can no longer be thought of as separated from other institutions within the organisation (Hjarvard, 2008). Mediatisation examines the long-term structural change in the role of the media in culture and society, in which the press acquire higher authority to define social reality and condition patterns of social interaction (Seidel, 2020). In today's technology-driven society, the mediatisation theory creates a paradigm shift from mediated media to structural transformations of the media in contemporary culture and society. From both health and cultural perspectives, the dangers of smoking have remained at the centre of scholarship with attendant health concerns. This theory presupposes that a culture that encourages smoking undermines the health of its citizens. Effective civic engagement with appropriate technology of information dissemination will be useful in eradicating smoking while driving.

\section{METHODOLOGY}

The study adopted a survey of company drivers (and ancillary staff) of Eastern Mass Transit and Onitsha South Mass Transit operating in Anambra State. These companies were selected based on antecedence of being registered transit companies, having an organised system of operation and reputation in commercial mass transit business in Anambra State. While Onitsha South Mass Transit has its parks in Onitsha, Awka and neighbouring states; Eastern Mass Transit operates within Nnewi, Onitsha, Awka and neighbouring states. The population comprised drivers willing to participate in the study. An effort was made to ensure that no driver was coerced into the investigation as it negates each company's policies. A sample of 57 drivers of both transport companies (Eastern Mass Transit, 30 and Onitsha South Mass Transit, 27) was randomly selected. The instrument of data collection was questionnaire, and data was analysed in tables.

\section{DATA PRESENTATION AND DISCUSSIONS}

Table 1: Attitudes of drivers of Eastern Mass Transit and Onitsha South Mass Transit on smoking and driving

Do you smoke at all? Time of smoking $\quad$ Health risks of smoking


NNAMDI AZIKIWE UNIVERSITY

Journal OF COMMUNICATION WND MEDI STUDIES

Volume 2 Number 1 Jan-Mar Issue

ISSN:2756-486X (Online)

DOI: doi.org/10.47851/naujocommed.v2i1.107

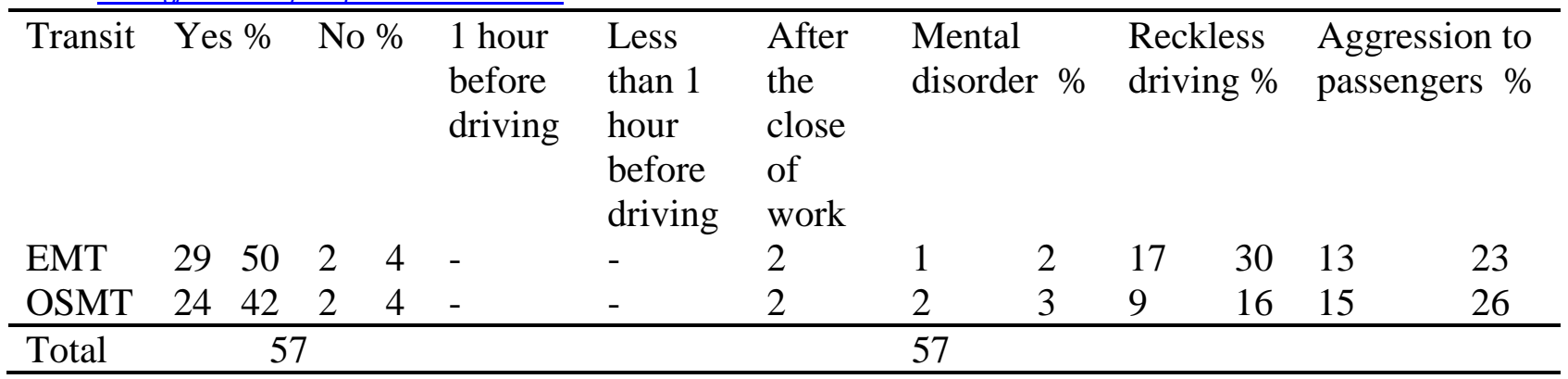

The responses above indicate that most drivers of both companies do not smoke all. Few drivers that smoke do so at the close of work. The implication is that there is reduced chance of driving under the influence of inhalable substances. However, there is even awareness of the dangers of smoking tobacco and driving. All drivers (whether smoking or not) understood the dangers of smoking. Although a reasonable number of drivers identified reckless driving as a risk; a significant index is aggression to passengers. This implies that a driver under the influence of inhalable substance may engage in verbal assaults with passengers in the course of driving. This is dangerous as it distracts a driver.

Table 2: Management Policies of select Mass Transit companies on smoking and driving

Does your company punish smoking Type of punishment for smoking drivers drivers?

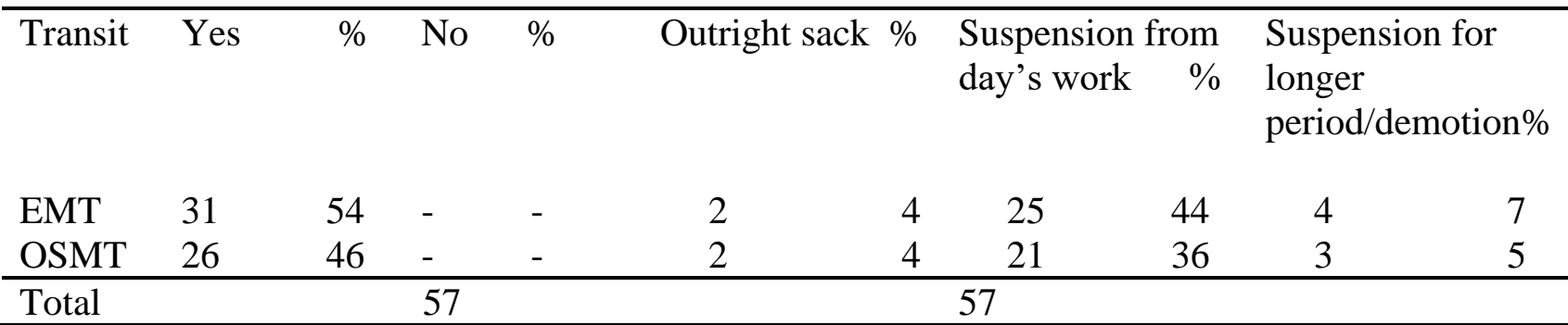

All drivers (Eastern Mass Transit and Onitsha South Mass Transit) agreed that respective management policies recommend the punishment of offenders. On the type of punishment, both transport companies adopt a similar measure of suspending offenders for a day's work usually on the day of the offence. This means that such a driver is never allowed to drive a company bus for that day. Apart from short suspension, an offender may be suspended for an extended period of 2 weeks or a month before he is allowed to drive company bus. In cases of repeated smoking offences, management may demote a driver to ancillary staff. The study found that drivers are not quickly sacked.

Table 3: Effectiveness of digital media in information dissemination on the dangers of smoking on wheels among drivers of select Mass Transit companies

\begin{tabular}{|c|c|}
\hline $\begin{array}{l}\text { Use of digital media for information } \\
\text { (Smart Phone) }\end{array}$ & $\begin{array}{l}\text { Effectiveness of digital media for information on dangers } \\
\text { of smoking and driving }\end{array}$ \\
\hline $\begin{array}{llll}\text { Transit } & \text { Yes } & \% & \text { No }\end{array}$ & $\begin{array}{lllll}\text { Very effective } \% & \text { Ineffective } & \% & \text { I don't know } & \%\end{array}$ \\
\hline
\end{tabular}

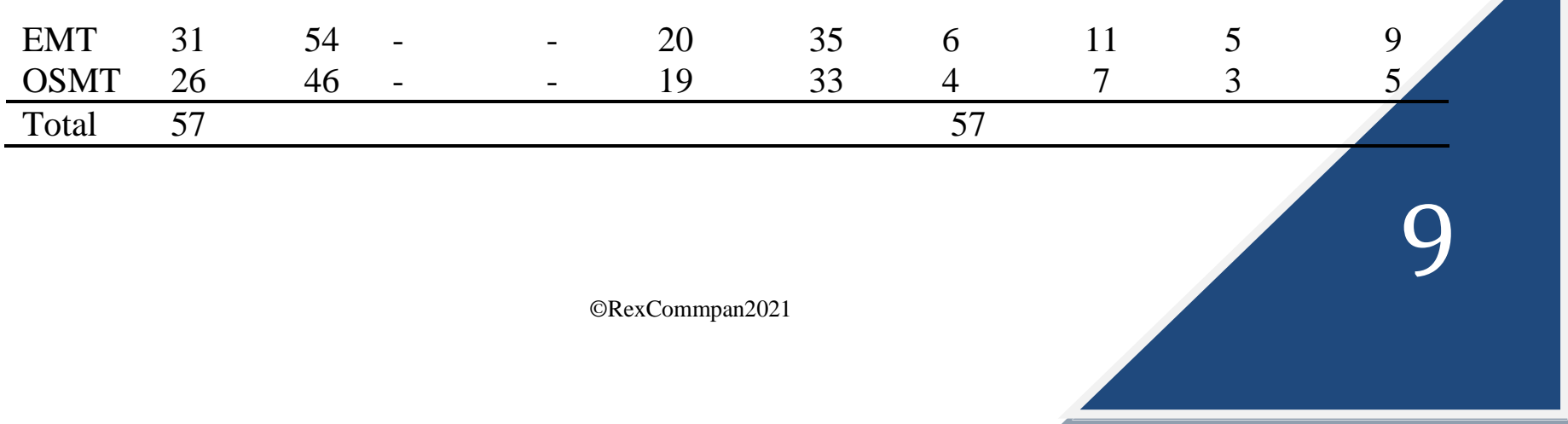


DOI: doi.org/10.47851/naujocommed.v2i1.107

All respondents use digital media (exceptionally smartphones) for information. A significant number of respondents attests to effective use of digital media for information on dangers of smoking and driving.

Table 4: Effectiveness of civic engagement on the dangers of smoking and driving among drivers of select Mass Transit companies

\begin{tabular}{|c|c|c|c|c|c|c|c|c|}
\hline \multicolumn{5}{|c|}{ Mode of Civic Engagement } & \multicolumn{4}{|c|}{ Effectiveness of Civic Engagement } \\
\hline \multirow[b]{2}{*}{ Transit } & \multicolumn{2}{|c|}{ Workshop } & \multicolumn{2}{|c|}{$\begin{array}{l}\text { Use of internal } \\
\text { memos/SMS }\end{array}$} & \multicolumn{2}{|c|}{ Workshop } & \multicolumn{2}{|c|}{$\begin{array}{l}\text { Use of internal } \\
\text { memos/SMS }\end{array}$} \\
\hline & $\begin{array}{l}\text { Yes } \\
\%\end{array}$ & $\begin{array}{l}\text { No } \\
\%\end{array}$ & $\begin{array}{l}\text { Yes } \\
\%\end{array}$ & $\begin{array}{r}\text { No } \\
\%\end{array}$ & $\begin{array}{l}\text { Effective } \\
\%\end{array}$ & $\begin{array}{l}\text { Ineffective } \\
\%\end{array}$ & $\begin{array}{l}\text { Effective } \\
\%\end{array}$ & $\begin{array}{l}\text { Ineffective } \\
\%\end{array}$ \\
\hline EMT & $8(14)$ & - & 23(40) & - & $6(11)$ & $25(43)$ & $31(54)$ & - \\
\hline OSMT & $4(7)$ & - & $22(39)$ & - & $2(4)$ & $24(42)$ & $25(44)$ & $1(2)$ \\
\hline Total & & 57 & & & & & & \\
\hline
\end{tabular}

All respondents identified modes of civil engagements. A significant number of respondents agreed that managements (Eastern Mass Transit and Onitsha South Mass Transit) use more of internal memos/SMS. They also attested to the effectiveness of this mode of civic engagement. This is justified on the premise that commercial driving is not an office work; thus, drivers are always on transit from one destination to another. The transit company managements adopt the use of Short Message Services (SMS) for quick messages to drivers.

\section{CONCLUSION}

A gap in the study is the dearth of evidence of administration of psychological tests on drivers at the point of recruitment in order to ascertain drivers' level of mental alertness and susceptibility to alcoholism and smoking habits. The study therefore, recommends as follows:

a. There should be continuous and sustained media messages on the dangers of smoking on wheels. The use of digital media such as smartphone is recommended, however media messages should ensure that drivers do not make or answer calls while driving.

b. Management of registered mass transits should ensure there are periodic workshops for drivers where officials of road regulatory agencies will interact with drivers on the dangers of smoking and driving.

c. Management should map out specific time for drivers to interact with management. A face-to-face type of meeting will help management address key issues affecting drivers. In cases where it is impossible to hold physical meetings, management can create company social media platforms for drivers so they can always get information regularly.

d. There is a need for psychological tests on drivers before recruitment. This exercise will help management to detect potential smokers and illicit drug users.

\section{REFERENCES}

Alonso, F., Esteban, C., Useche, S. and Faus, M. (2017). Smoking while driving: frequency, motives, perceived risk and punishment. World Journal of Preventive Medicine, 5(1), $1-9$.

Anand, S., Gupta, M. and Kwatra, S. (2013). Social media and effective health 
communication. International Journal of Social Science and Interdisciplinary Research, 2(8). 39- 46

Benjamin, R. (2010). A report of the surgeon-general on how tobacco smoke causes disease. www.surgeongeneral.gov. Accessed on 4-6-2020.

Camino, L. and Zeldin, S. (2002). From periphery to center: pathways for youth civic engagement in the day-to-day life of communities. Applied Development Science, 6(4), 213-220.

Davis, R., Gilpin, E., Loken, B., Viswanath, K. and Wakefield, M. (2008). The role of the media in promoting and reducing tobacco use. National Cancer Institute. https://cancercontrol.cancer.gov/brp/tcrb/monographs/19/m19_complete.pdf. Accessed on 5-6-2020.

Delli, M. (2017). Civic engagement. http://www.apa.org/education/undergrad/civicengagement.aspx. Accessed on 3-6-2020.

Dubow, T., Devaux, A. and Manville, C. (2017). Civic engagement: how can digital technology encourage greater engagement in civil society? http://www.rand.org/t/PE253. Accessed on 2-6-2020.

Encarta (2009). Smoking. Redmond, WA: Microsoft Corporations.

Federal Road Safety Corps (2020). Nigeria Highway (2015-2020) Code Section D: Traffic Offences at a Glance. http://www.highwaycode.com.ng/section-d-traffic-offences-ata-glance.html. Accessed on 5-6-2020.

Federal Republic of Nigeria Official Gazette (2015). National Tobacco Control Act, 2015 Act No. $9 . \quad$ https://www.tobaccocontrollaws.org/files/live/Nigeria/Nigeria\%20\%20TCA\%20-\%20national.pdf. Accessed on 4-6-2020.

Folkerts, J. and Lacy, S. (2004). The media in your life. India: Dorling Kindersley Pvt Limited licensed by Pearson Educational Inc.

Gupta, S. and Kumar, V. (2018). A study on effects of smoking on society: a case study. MOJ Public Health, 7(4), 192-194.

Hartman, R. and Huestis, M. (2013). Cannabis effects on driving skills. Clinical Chemistry, $59(3), 1-30$.

Hilton, M. (2015). Smoking. Chicago: Encyclopedia Britannica.

Hjarvard, S. (2008). The Mediatization of religion: a theory of the media as agents of religious change in northern lights. Yearbook of Film \& Media Studies. Bristol: Intellect Press.

Kenechukwu, S. (2014). Mass communication: an introduction to sociology of mass media. Nnewi: CathCom Press. 
DOI: doi.org/10.47851/naujocommed.v2i1.107

Kenechukwu, S. (2014). Film production: criticism, aesthetics, theories and documentary.

Orlu: Holy Innocents Press.

Lu, Y. (2017). "It's not a life or death thing": A grounded theory study of smoking decisions among Chinese Americans. The Qualitative Report, 22(3), 797-817

Mossberger, K., Tolbert, C. J. and McNeal, R.S. (2007-10-12). Digital citizenship: the internet, society, and participation. Cambridge, MA: MIT Press.

National Safety Council (2017). Research document on marijuana and driving. https://www.nsc.org/Portals/0/Documents/NSCDocuments_Advocacy/Divisions/ADI D/Position-on-Cannabis-and-Driving.pdf. Accessed on 5-6-2020.

Nayyar, S. (2016). Digital media and society: implications in a hyperconnected era. Geneva: World Economic Forum

NTCB (2009). The National Tobacco Control Bill, NTCB 2009. http://nigerianationaltobaccocontrolbill.blogspot.com/2009/07/groups-rally-supportfor-tobacco-bill.html. Accessed on 6-6-2020.

Oladepo, O., Oluwasanu, M. and Abiona, O. (2018). Analysis of tobacco control policies in Nigeria: historical development and application of multi-sectoral action. BMC Public Health, 18 (1), 1-53.

O'Hegarty, M., Pederson, L., Nelson, D., Mowery, P., Gable, J. and Wortley, P. (2006). Reactions of young adult smokers to warning labels on cigarette packages. American Journal of Preventive Medicine 30 (6): 467-73.

Ozoh, O., Akanbi, M., Amadi, C., Vollmer, W. and Bruce, N. (2017). The prevalence of and factors associated with tobacco smoking behavior among long-distance drivers in Lagos, Nigeria. African Health Sciences, 17(4), 1100-1119.

Rheingold, H. (2008). Using participatory media and public voice to encourage civic engagement. Civic life online: learning how digital media can engage youth. In

Bennett et al (eds). MacArthur Foundation Series on Digital Media and Learning. Cambridge, MA: The MIT Press.

Seidel, N. (2020). Identify and discuss the similarities and differences between "mediation" and "mediatization". https://quizlet.com/71865681/simple. Accessed on 10-6-2020.

Smith, A., Carter, S., Dunlop, S., Freeman, B. and Chapman, S. (2017). Measured, opportunistic, unexpected and naïve quitting: a qualitative grounded theory study of the process of quitting from the ex-smokers' perspective. BMC Public Health, 17: 430

Smith, R. (2013). What is digital media? The Centre for Digital Media. https://thecdm.ca/news.what -is-digital-media. Accessed on 2-6-2020.

Sullman, M.J. (2012). An observational study of driver distraction in England. 
NNAMDI AZIKIWE UNIVERSITY Journal of COMMUNICATION AND MEDLA STUDIES

Volume 2 Number 1 Jan-Mar Issue

DOI: $\underline{\text { doi.org/10.47851/naujocommed.v2i1.107 }}$

Transportation Research, 15, 272-278.

Xenos, M. and Moy, P. (2007). Direct and differential effects of the Internet on political and civic engagement. Journal of communication, 57(4), 704-18. 